\title{
A briga de galos e a inconstitucionalidade da Lei Fluminense no 2.895/1998
}

O presente trabalho pretende contribuir para o estudo sobre a responsabilidade ambiental no âmbito penal, a descaracterização da briga de galo como manifestação cultural e o reconhecimento da inconstitucionalidade da Lei Fluminense n. 2.895/1998. Para tanto foi analisada doutrina sobre a matéria, especialmente no que tange aos aspectos gerais e peculiares existentes para a proteção da fauna e as divergências existentes sobre as diversas questões acerca da responsabilidade ambiental.

Palavras-chave: Meio ambiente; Briga de galo; Responsabilidade penal ambiental.

\section{Cockfighting and the unconstitutionality of Fluminense Law no $2.895 / 1998$}

This paper aims to contribute to the study on environmental liability in criminal law, the mischaracterization of cockfighting as a cultural manifestation and recognition of the unconstitutionality of Fluminense Law $n$. 2.895/1998. For this was analyzed doctrine on the matter, especially with regard to general and specific aspects that exist for the protection of fauna and the differences on the various questions about environmental responsibility.

Keywords: Environment; Cockfight; Environmental criminal.

Topic: Direito Ambiental

Reviewed anonymously in the process of blind peer.
Received: $14 / 12 / 2019$

Approved: 20/04/2020
Cleuber Lúcio Santos Júnior (iD

Universidade do Estado de Minas Gerais, Brasil

http://lattes.cnpq.br/4643853302414634

http://orcid.org/0000-0003-4393-1465

cleuber.junior@uemg.br

Virginia Xavier Borges Silva (id

Universidade de Coimbra, Portugal

http://lattes.cnpq.br/3488120379693490

http://orcid.org/0000-0001-7163-7103

virginia.xborges@gmail.com
Referencing this:

SANTOS JUNIOR, C. L.; SILVA, V. X. B.. A briga de galos e a inconstitucionalidade da Lei Fluminense $n$ ㅇ 2.895/1998. Libro Legis, v.2, n.1, p.1-11, 2020. DOI: http://doi.org/10.6008/CBPC26746409.2020.001.0001 


\section{INTRODUÇÃO}

As espécies de responsabilidade na esfera ambiental estão previstas no artigo 225 , §3으, da Constituição Federal de 1988, que prevê que as atividades que importem em prejuízo ao meio ambiente serão punidas penal, administrativa e civilmente. No entanto, só se deve buscar a tutela penal ambiental quando as outras esferas de responsabilização não se mostrarem suficientes para resguardar a integridade do bem jurídico tutelado.

A responsabilidade penal ambiental, assim como a responsabilidade administrativa, foi disciplinada pela Lei no 9.605/1998, que prevê instrumentos de repressão contra as condutas e atividades lesivas ao meio ambiente. De acordo com esta lei, a prática de qualquer conduta por ela tipificada, seja por pessoa física ou jurídica, sujeita o infrator às penas nela previstas. Respondem, no entanto, por omissão, o diretor, o administrador, o membro de conselho e de órgão técnico, o auditor, o gerente, o preposto ou mandatário de pessoa jurídica, que, sabendo do cometimento da infração nada fizer para evitá-la.

A Constituição Federal de 1988, em seu artigo 225, §1으, inciso VII, determina a proteção da fauna, sendo vedadas as práticas que coloquem em risco sua função ecológica, provoquem a extinção de espécies ou submetam os animais a crueldade. O dispositivo, porém, não definiu que espécie de fauna protege, e, por isso, a única ilação possível é no sentido de que todas as espécies pertencentes à fauna estão protegidas pelo dispositivo da Lei Maior.

A promoção de briga de galos, além de caracterizar prática criminosa tipificada na legislação ambiental, configura conduta atentatória à Constituição da República, que veda a submissão de animais a atos de crueldade, cuja natureza perversa, à semelhança da 'farra do boi', não permite sejam eles qualificados como inocente manifestação cultural, de caráter meramente folclórico.

A proteção jurídico-constitucional dispensada à fauna abrange tanto os animais silvestres quanto os domésticos ou domesticados, nesta classe incluídos os galos utilizados em rinhas, pois, o texto da Lei Fundamental vedou, em cláusula genérica, qualquer forma de submissão de animais a atos de crueldade.

Essa especial tutela, que tem por fundamento legitimador a autoridade da Constituição da República, é motivada pela necessidade de impedir a ocorrência de situações de risco que ameacem ou que façam periclitar todas as formas de vida, não só a do gênero humano, mas, também, a própria vida animal, cuja integridade restaria comprometida, não fora a vedação constitucional, por práticas aviltantes, perversas e violentas contra os seres irracionais, como os galos de briga ('gallus-gallus').

Diante disso, indaga-se: trata-se, a briga de galos, de uma exteriorização de uma prática cultural coletiva? A edição de leis municipais permitindo a briga de galos fere o ordenamento jurídico pátrio, especialmente por tentar regular uma prática que é considerada crime? A Lei fluminense no 2.895/1998 - RJ, face a Constituição da República de 1988 e sua consequente conferência ao meio ambiente, de status de 'direito fundamental', bem como a crescente preocupação no que tange às suas diversas formas de sua tutela/proteção, pode/deve ser considerada inconstitucional?

A relevância da pesquisa evidencia-se na medida em que revela os argumentos que a prática da briga 
de galos expõe os animais a condições violentas, bem como refuta a ideia de que a mesma se trataria de uma exteriorização de manifestação cultural, não devendo, portanto, sofrer ingerências com fins a sua proibição, e sugere a inconstitucionalidade da Lei Fluminense n.o 2.895/1998 - RJ, com fins de demonstrar mais uma forma de tutela da fauna e, consequentemente, a do meio ambiente, concluindo que a briga de galos é prática social ultrapassada e vai de encontro à construção progressiva de uma consciência pela proteção aos animais

Utilizam-se como procedimentos metodológicos a pesquisa bibliográfica e documental com o levantamento de decisões judiciais e análise da legislação aplicável. A partir destes procedimentos, conclui-se que existem no Brasil garantias legais para coibir as práticas que podem representar crueldade contra os animais.

Nesse sentido que procurou-se realizar este trabalho acerca da responsabilidade ambiental, verificando o posicionamento da doutrina e da jurisprudência quanto à questão da responsabilidade criminal e um de seus temas mais divergentes e problemáticos, objetivando um melhor entendimento sobre o assunto e verificando quais os aspectos positivos e negativos do trabalho que vem sendo desenvolvido na legislação e doutrina, além de observar como tem sido o posicionamento do Supremo Tribunal Federal sobre o tema, nessa busca de proteção e preservação do meio ambiente, bem fundamental na vida de todas as espécies.

\section{METODOLOGIA}

Para a elaboração do presente trabalho foi analisada doutrina sobre a matéria, especialmente no que tange aos aspectos gerais e peculiares existentes para a proteção da fauna e as divergências existentes sobre as diversas questões acerca da responsabilidade ambiental. Também foi realizada uma análise da decisão proferida pelo Supremo Tribunal Federal - a Ação Direta de Inconstitucionalidade no 1.856 - Rio de Janeiro, especialmente para verificar como esse se posicionou sobre as divergências existentes sobre o assunto.

\section{DISCUSSÃO TEÓRICA}

\section{Responsabilidade Penal Ambiental}

A previsão de crimes especificamente ecológicos, esteja ela compreendida no Código Penal ou expressa em leis especiais é, de qualquer modo, a única forma para assegurar aos valores ambientais aquela proteção 'imediata' de que necessitam no momento atual, surgindo, 'assim, no direito penal recente, uma tipologia de seus interesses ecológicos que se apresentam sempre, em todas as experiências legislativas que se vêm a fazer na matéria'.

Quanto ao crime de dano ecológico, ocorre sempre que a tutela emprestada ao bem natural considere o momento em que se verificam os efeitos da inquinação e o dano constitui-se numa alteração da situação preexistente em razão da ação de determinado sujeito, o crime comportará a valoração da lesão efetiva de um bem ambiental. Por isso, hipóteses de crimes de danos, nesse campo, não são frequentes, 
porque, na prática, são de difícil aplicação.

Nos tempos modernos, a tendência é antecipar a proteção do ambiente natural, do momento do dano ao momento do exercício da atividade perigosa aos bens ecológicos, quando não do instante da simples detenção ou produção de substâncias poluentes. A atenção do legislador tem sido cada vez mais nesse sentido, obcecada que se acha pela necessidade de prevenir o fenômeno, reprimindo as condutas predatórias. Afastam-se os crimes ecológicos, consequentemente, sempre mais da lesão efetiva do bem jurídico, para construírem uma linha avançada de defesa contra a poluição.

Mas na doutrina mais atenta e nas experiências legislativas de vanguarda vai se afirmando um outro modo de considerar o problema. Partidas das dificuldades sabidas de encontrar o legislador penal, para delimitar o âmbito e a intensidade da tutela a ser emprestada aos bens ambientais, sugere-se que a proteção do ambiente seja confiada principalmente à autoridade administrativa, a quem cabe a obrigação de regulamentar os fatores poluentes, de conceder autorizações para o exercício de atividades perigosas, de impor limitações, cautelase proibições com relação a eles. O Direito Penal viria a desenvolver a função secundária de punir a violação de prescrições administrativas.

\section{A briga de galos e a ação direta de inconstitucionalidade № 1.856-RJ}

Alguns municípios promulgam leis permitindo brigas de galo. Por exemplo, a Lei no 1.810, de 07.04.1998, do município de Encruzilhada do Sul/RS. Referidas leis são de manifesta inconstitucionalidade, pois pretendem tornar a regular uma prática que é considerada crime. Só à União cabe legislar sobre Direito Penal (artigo 22, I, da CF). Além disso, é dever do Poder Público, zelar pelo meio ambiente sadio (artigo 225, da (F). Independentemente da arguição de inconstitucionalidade pelas vias próprias, cabe ao Ministério Público estadual zelar para que tal prática não se desenvolva, propondo as ações penais contra seus infratores.

Para a tipificação do crime do artigo 32, da Lei no 9.605/1998, deve ficar demonstrado que a conduta do agente - de patrocinar rinhas de galo - acarretava abuso e maus tratos aos animais, podendo ocasionarIhes ferimentos, mutilações e eventualmente até a morte:

Apelação crime. Maus tratos a animais. Rinha de galo. Art. 32, da Lei 9.605/1998. Provada a participação do apelante na prática do delito previsto no art. 32, da Lei 9.605/1998, maus tratos a animais, com galos lesionados e incitados à violência, inclusive com biqueiras metálicas e outros apetrechos utilizados na rinha de galos, resta configurado maus tratos aos animais, estando caracterizados todos os elementos do tipo, confirmando-se a sentença condenatória. Apelação improvida. (BRASIL, 1998a)

A Ação Direta de Inconstitucionalidade 1.856 - Rio de Janeiro, teve como relator o Excelentíssimo Ministro do STF, Celso de Mello, Requerente, o Procurador-Geral da República e, como interessados, o Governador do Estado do Rio de Janeiro e a Assembleia Legislativa do referido Estado da Federação.

Tratou-se de ação direta de inconstitucionalidade, que, proposta pelo Procurador-Geral da República, teve por finalidade questionar a validade jurídico-constitucional da Lei estadual № 2.895, de 20 de março de 1998, do Estado do Rio de Janeiro.

A Lei fluminense № 2.895/1998 foi editada com o objetivo de legitimar a realização de exposições e 
de competições entre aves não pertencentes à fauna silvestre, possuindo o seguinte conteúdo normativo:

LEI № 2.895, DE 20 DE MARÇO DE 1998. AUTORIZA A CRIAÇÃo E A REALIZAÇÃo DE EXPOSIÇÕES E COMPETIÇÕES ENTRE AVES DAS RAÇAS COMBATENTES (FAUNA NÃO SILVESTRE) PARA PRESERVAR E DEFENDER O PATRIMÔNIO GENÉTICO DA ESPÉCIE GALLUS- GALLUS.

Art. 10 - Fica autorizada a criação e a realização de exposições e competições entre aves das Raças Combatentes em todo o território do Estado do Rio de Janeiro, cuja regulamentação fica restrita na forma da presente Lei. (...). (BRASIL, 1998b)

O autor da ação direta sustentou a inconstitucionalidade de referido diploma normativo, enfatizando que tal regra - ao 'autorizar a criação e a realização de exposições e competições entre aves das raças combatentes (fauna não silvestre)' - ofendeu o preceito inscrito no artigo 225 , 'caput', c/c o seu § 1ำ, inciso VII, da Constituição da República.

Eis, em síntese, os fundamentos que, invocados pelo eminente Procurador-Geral da República, buscaram justificar a pretensão de inconstitucionalidade ora deduzida em sede de controle normativo abstrato:

(...) Com efeito, sem embargo da motivação que estaria a revestir a edição do diploma normativo cuja validade jurídico-constitucional é ora questionada na presente ação direta de inconstitucionalidade, o certo é que é inegável que a Lei Estadual $n^{\circ} 2.895 / 98$ possibilita a prática de competição que submete os animais a crueldade, como é cediço dizer em se tratando de rinhas de brigas de galos, em flagrante violação ao mandamento constitucional proibitivo de práticas cruéis envolvendo animais. (BRASIL, 2011)

Acrescenta o eminente jurista ainda que, ao contrário de buscar proteger a fauna e a flora como medida para tornar efetivo o direito constitucional ao meio ambiente ecologicamente equilibrado, e observar a vedação, na forma da lei, das práticas que submetam os animais a crueldade, teria atuado o legislador estadual fluminense ao largo da norma programática constitucional.

Importante enfoque traz o Douto Procurador em relação à antinomia entre a lei estadual impugnada e o texto constitucional nos seguintes termos:

Revela-se, portanto, a antinomia entre o disposto na lei estadual e o texto constitucional, na medida em que se afastou o legislador estadual da observância ao princípio da intervenção estatal obrigatória na defesa do meio ambiente (art. 225, 'caput'), que torna compulsória a atividade dos órgãos e agentes estatais, não sendo despiciendo citar, a título de ilustração, o magistério do llustre Professor Jorge Bustamante Alsina, para quem 'Corresponde al Estado adoptar las disposiciones o normas administrativas que regulen tales actividades en vista de la preservación del ambiente, que le corresponde en ejercicio de los poderes de polícia inherentes a la Nación y a las províncias para proteger la vida, la propriedad, la seguridad la moralidad y la salud de los habitantes (...) ('in', Derecho ambiental - Abeledo-Perrot-Buenos Aires, p. 61/62)'. (BRASIL, 2011)

A Assembleia Legislativa do Estado do Rio de Janeiro, ao prestar as informações que the foram solicitadas, manifestou-se pela improcedência da presenteação direta, propugnando, em consequência, pelo reconhecimento da plena validade constitucional da norma ora impugnada:

Em atendimento ao Ofício no 336/P, solicitando informações para instruir a AÇÃO DIRETA DE INCONSTITUCIONALIDADE № 1856, que tem por objeto a LEI ESTADUAL № 2895, de 20.03.98, encaminhamos a V. Ex. a cópia do inteiro teor do processo legislativo que teve origem no PROJETO DE LEI № 1285/95, dando origem à lei acima referida. Além da descrição do aludido processo legislativo, oportuno se nos parece enfatizar que, 'in casu', ao se positivarem regras, em lei bem fundamentada em seus diferentes aspectos, preocupação houve, por parte desta Casa Legislativa, em regulamentar-se atividade que, a partir da sua promulgação, passa-se a controlar e a fiscalizar, oficialmente, diversas 
associações e federações esportivas do setor, sob autorização e supervisão do Poder Público, exercida em locais apropriados, assegurada a observância de regras de estrita segurança. É inegável que, sob o ponto de vista social, trata-se de um forte fator de integração de comunidades do interior deste Estado, como de resto ocorre em outros Estados, a gerar, inclusive, um apreciável número de empregos, sendo que no Rio de Janeiro há, aproximadamente, 100 (cem) rinhas e mais de 70 (setenta) centros esportivos. (BRASIL, 2011)

Nota-se que a Assembleia Legislativa do Rio de Janeiro, através de seu procurador, traz à baila argumentos estritamente relativos à necessidade de regulamentação da atividade já existente, sem prejuízo de ações positivas do ente federativo no que tange aos atos de autorização e supervisão. Ademais, acrescenta que o sob do ponto de vista social, tratar-se-ia de um 'forte fator de integração de comunidades do interior do Estado', a gerar, inclusive, um apreciável número de empregos, e, o mais alarmante, traz dados de que em todo o Estado haveria, aproximadamente, 100 rinhas e mais de 70 'centros esportivos'. E, continua:

Sem prejuízo dessas primeiras considerações, cumpre-nos enfatizar que, no plano jurídico, ao se promover o cotejo da lei estadual, nesta via impugnada, com o preceito do art. 225, 'caput' $c / c \S 1^{\circ}$, inciso VII, da lei fundamental, verifica-se que afronta inocorre à norma que se extrai desse texto. Com efeito e segundo os ensinamentos do emérito Prof. José Afonso da Silva ('in' 'Direito Ambiental Constitucional', Malheiros, São Paulo, 2a ed., 1995, p. 128 'usque' 129), ao tecer comentários sobre esse dispositivo constitucional, assevera que a Constituição de 1988 não mais comete competência exclusiva da União para legislar sobre caça, pesca e fauna, porém como competência concorrente entre ela, os Estados e o Distrito Federal (art. 24, inciso VI), limitando-se a legislação federal a estabelecer normas gerais sobre a matéria. Enquanto a dos Estados e Distrito Federal, a estabelecer normas suplementares daquelas. (...) Não é de se incluírem os animais domésticos e domesticados, nem os de cativeiro, criatórios e de zoológicos particulares, devidamente legalizados, remata o emérito constitucionalista. (BRASIL, 2011)

Destaca-se que de forma desproporcional, a Assembleia daquele Estado argumenta que o que está a ocorrer no caso sub judice é uma tentativa de se estender o objeto da tutela ambiental ao galo de briga, e que segundo o Instituto Brasileiro de Meio Ambiente e dos Recursos Naturais Renováveis - IBAMA, é considerado ave doméstica, estando ela fora do âmbito material de incidência da norma constitucional:

Sucede que, na hipótese 'sub examen', pretende-se estender o objeto da tutela ambiental ao galo de briga que, consoante pronunciamento formal do Instituto Brasileiro de Meio Ambiente e dos Recursos Naturais Renováveis - IBAMA, entidade vinculada ao Ministério do Meio Ambiente, dos Recursos Hídricos e da Amazônia Legal, é considerado como ave doméstica, escapando, pois, daquela de âmbito material de incidência do comando constitucional. (BRASIL, 2011)

Com a finalidade de 'enriquecer' e legitimar os argumentos tecidos, a Casa Legislativa minimiza a violência dos combates entre galos, buscando perquirir o conteúdo normativo ou a chamada 'ratio' da norma na expressão: '(...) vedada as práticas que submetam os animais a crueldade', aduzindo que, diferentemente da caça, tiro ao pombo ou farra do boi, as aves lutam sem qualquer interferência direta do homem. Veja-se:

Ainda que se admitisse, 'ad argumentandum tantum', que estivesse o galo combatente incluído na fauna silvestre, mesmo assim não há como prosperar a pretensão na inicial deduzida. Nesse sentido, cumpre aduzir, ao se perquirir o conteúdo semântico, o sentido normativo contido na expressão: '(...) vedada as práticas que (...) submetam os animais a crueldade', destacada na peça vestibular, verifica-se que o seu sentido é o de coibir práticas em que há ação do homem contra o animal, assim como ocorre na caça, no tiro ao pombo, na conhecida farra do boi. Na hipótese do chamado 'galismo' as aves lutam sem qualquer interferência direta do homem; brigam por seu espírito atávico, nada havendo a forçá-las a combater. (BRASIL, 2011) 
Arrematando sua tese:

Assim e sob o ponto de vista sistemático, não se vislumbra na Carta Magna qualquer regra a restringir ou mesmo vedar a atividade regulada no referido diploma legal estadual, sendo certo que, ante as circunstâncias históricas, que informaram a origem do preceito constitucional não se referem ao galismo, porém à chamada 'farra do boi', repita-se, este era o fim perseguido pelo legislador constituinte. Quer quanto à sua letra, quer quanto ao seu espírito, a 'ratio' que se extrai é a conformação da lei impugnada à Constituição Federal, não se vislumbrando, sob o ponto de vista dogmático, qualquer violação (...). (BRASIL, 2011)

Por fim, conclui que o legislador estadual, ao ter de exercer sua atividade discricionária políticolegislativa, se vê num 'beco sem saída', ou seja, tendo de optar por uma dentre duas opções, quais sejam: 1) permanecer inerte, nada regulamentando; ou 2) ou disciplinar a atividade, deixando clara a escolha feita, ou seja, esta última, devendo ser julgado improcedente o pedido, ante a 'inquestionável' constitucionalidade da Lei no $2895 / 98$ :

Em síntese, inocorre qualquer mácula, sob o prisma jurídico, na lei no 2895/98, podendose, quando muito, questionar o ato legislativo no plano meramente filosófico, se este fosse o plano em que debatida fosse a questão posta. Entrementes e admitindo-o, ainda uma vez tão-só para efeito de debate, mesmo assim não há como prosperar a pretensão na inicial deduzida, pois o legislador estadual deparou-se, no exercício de atividade discricionária político-legislativa, com duas opções: a) permanecer inerte, nada regulamentando; ou b) disciplinar a atividade. Preferiu-se a segunda, posto que o controle, a finalização da atividade se constituem em atos que materializam o exercício regular do poder de polícia, na verificação da normalidade da atividade, consoante as normas legais e regulamentares pertinentes. Em face de tais razões, esperamos e confiamos que: a) não se conceda a liminar postulada, ante a manifesta ausência, 'in casu', dos seus pressupostos; b) seja julgado improcedente o pedido, ante a inquestionável constitucionalidade da Lei no 2895/98. (BRASIL, 2011)

O Senhor Governador do Estado do Rio de Janeiro, por sua vez, ao pedir a improcedência da presente ação direta, apoiou-se, em síntese, nas seguintes informações:

Cabe enfatizar a inépcia da inicial, já que o autor, sob a sumária argumentação que lhe parece ser suficiente para sustentar o pedido, não indica quais os dispositivos da Lei impugnada entendem serem frontalmente contrários à Constituição Federal, assim como não fundamenta, de forma especificada, porque cada um dos dispositivos, do ato impugnado são inconstitucionais. Ademais, guardando o mesmo defeito, por outro ângulo, a inépcia da exordial emerge, também, da falha oriunda da 'narração dos fatos não decorrer logicamente a conclusão' (art. 295, parágrafo único, inciso II, do CPC). Ora, se é que o nódulo do pedido é lastreado na possível crueldade com animais, não se tratando de hipótese submetida à ficção legal que assim qualifique a conduta determinada, só pode ser constatada mediante a produção de prova, o que em sede de controle concentrado e 'abstrato' de constitucionalidade é inadmissível. Com a devida vênia as deformidades do pedido recomendam o não conhecimento da Ação Direta, como comandam os incisos I a III, do art. 295, do Código de Processo Civil. (BRASIL, 2011)

Ainda do ponto de vista formal/processual, bem como semântico/interpretativo da norma objeto de impugnação, questiona o Chefe do Poder Executivo do Estado, inclusive, a sua precisão, tangenciando o mérito propriamente dito, argumentando no seguinte sentido:

(...) não se enxerga na lei atacada onde ela possa agredir o meio ambiente, ou como ela desprotegeria a fauna, prejudicaria a função ecológica, provocaria extinção de espécies ou submeteria animais à crueldade por práticas que, de acordo com os dispositivos citados da Constituição, sejam definidas 'na forma da lei'.

A natureza limitada da eficácia do comando constitucional imprescinde da definição de quais são essas práticas que, ademais, uma vez fixadas, se transgredidas, ensejariam uma hipótese de 'ilegalidade' e 'não' de 'inconstitucionalidade'. A indefinição deixa ao léu e sob 
o crivo do contexto probatório saber-se, por exemplo, se a prática de corridas de cavalos poderia ser enquadrada como conduta a ser programaticamente combatida, ante a falta de tipificação legal, levando à subjetividade, a conceitos fluídos e pouco palpáveis, à arbitrariedade, ao abuso de poder e aí sim à flagrante contrariedade do texto constitucional onde prevê que nenhuma conduta terá comando senão o da lei (art. 5으, II, da CF), assim como ao seu mais importante princípio norteador de todo o resto do sistema: a democracia (art. 1ㅇ da CF). Não há, pois, no texto impugnado, ofensa direta ao texto constitucional, que ao contrário do alegado, traz em si regras de preservação e de poder de polícia, para a segurança de eventos que envolvem a participação de grande número de indivíduos, ordenando uma das formas de convívio social. (BRASIL, 2011)

A concluir, o Governador pede que o Supremo Tribunal não conheça da ação se acatada a preliminar ou, se ultrapassada (observância do princípio da eventualidade), que, no mérito, a julgue improcedente:

Espera-se, por fim, como consequência das informações prestadas, que esse Pretório Excelso não conheça da ação, por força da preliminar levantada ou, se ultrapassada, o que se cogita em honra do princípio da eventualidade, que, no mérito, a julgue improcedente.

O Plenário do Supremo Tribunal Federal, ao deferir o pedido de medida cautelar formulado pelo autor da presente ação direta, decidiu, por unanimidade de votos, 'suspender, até final julgamento da ação direta, a execução e a aplicabilidade da Lei no 2.895, de 20.03.1998, do Estado do Rio de Janeiro', fazendo-o em acórdão assim ementado:

'CONSTITUCIONAL. MEIO AMBIENTE. ANIMAIS: PROTEÇÃO: CRUELDADE. 'BRIGA DE GALOS'. I. - A Lei 2.895, de 20.03.98, do Estado do Rio de Janeiro, ao autorizar e disciplinar a realização de competições entre 'galos combatentes', autoriza e disciplina a submissão desses animais a tratamento cruel, o que a Constituição Federal não permite: C.F., art. 225, $\S 1$ 1, VII. II. - Cautelar deferida, suspendendo-se a eficácia da Lei 2.895, de 20.03.98, do Estado do Rio de Janeiro'. (BRASIL, 2011)

O eminente Advogado-Geral da União, acolhendo as manifestações da Assembleia Legislativa e do Governador do Estado do Rio de Janeiro, opinou pela improcedência do pedido.

O Ministério Público Federal, no entanto, em pronunciamento da douta Procuradoria-Geral da República, opinou pela procedência do pedido, fazendo-o com apoio em parecer que está assim ementado:

Ação Direta de Inconstitucionalidade. Direito Constitucional e Ambiental. Lei Fluminense no 2.895, de 20 de março de 1998, que regulamentou a 'rinha de galos' como esporte. Preliminar de inépcia rejeitada. Desnecessária a impugnação específica e individualizada de cada dispositivo da lei atacada. Inconstitucionalidade presente em todo o texto legal e demonstrada pelo autor. Mérito. Artigo 225, § 1으, inciso VII, da Constituição Federal. A proibição de submissão de animais a práticas cruéis abrange todos exemplares da fauna, ainda que domesticados e em cativeiro. Parecer pela procedência da ação.

Feitas tais observações, passou-se a julgar o fundo da presente controvérsia constitucional, instaurada em razão da evidente inconstitucionalidade da Lei no 2.895/1998, editada pelo Estado do Rio de Janeiro.

O fundamento em que se apoiou a pretensão de inconstitucionalidade do diploma legislativo em referência reside na prática de atos revestidos de inquestionável crueldade contra aves das Raças Combatentes ('gallus-gallus') que são submetidas a maus-tratos, em competições promovidas por infratores do ordenamento constitucional e da legislação ambiental, que transgridem, com seu comportamento delinquencial, a regra constante do inciso VII, do § 1ํ, do art. 225, da Constituição da República, que contém prescrição normativa cujo teor está assim enunciado:

\section{Art. 225}

$\S 1$ 으 - Para assegurar a efetividade desse direito, incumbe ao poder público: 
VII - proteger a fauna e a flora, vedadas, na forma da lei, as práticas que coloquem em risco sua função ecológica, provoquem a extinção de espécies ou submetam os animais a crueldade. (BRASIL, 1988)

Vê-se, daí, que o constituinte objetivou, com a proteção da fauna e com a vedação, dentre outras, de práticas que "submetam os animais a crueldade", assegurar a efetividade do direito fundamental à preservação da integridade do meio ambiente, que traduz conceito amplo e abrangente das noções de meio ambiente natural, de meio ambiente cultural, de meio ambiente artificial (espaço urbano) e de meio ambiente laboral, consoante ressalta o magistério doutrinário (FIORILLO, 2005).

É importante assinalar, neste ponto, que a cláusula inscrita no inciso VII, do § 1으, do artigo 225, da Constituição da República, além de veicular conteúdo impregnado de alto significado ético-jurídico, justificase em função de sua própria razão de ser, motivada pela necessidade de impedir a ocorrência de situações de risco que ameacem ou que façam periclitar todas as formas de vida, não só a do gênero humano, mas, também, a própria vida animal, cuja integridade restaria comprometida por práticas aviltantes, perversas e violentas contra os seres irracionais (SILVA, 2003).

Resulta, pois, da norma constitucional invocada como parâmetro de confronto (CF, art. 225, § 10, VII), o sentido revelador do vínculo que o constituinte quis estabelecer ao dispor que o respeito pela fauna em geral atua como condição inafastável de subsistência e preservação do meio ambiente em que vivem os próprios seres humanos.

Evidente, desse modo, a íntima conexão que há entre o dever ético-jurídico de preservar a fauna (e de não incidir em práticas de crueldade contra animais), de um lado, e a própria subsistência do gênero humano em um meio ambiente ecologicamente equilibrado, de outro.

Cabe reconhecer, portanto, o impacto altamente negativo que representaria, para a incolumidade do patrimônio ambiental dos seres humanos, a prática de comportamentos predatórios e lesivos à fauna, seja colocando em risco a sua função ecológica, seja provocando a extinção de espécies, seja, ainda, submetendo os animais a atos de crueldade.

Daí a enorme importância de que se revestem os preceitos inscritos no art. 225, da Carta Política, que traduzem, na concreção de seu alcance, a consagração constitucional, em nosso sistema de direito positivo, de uma das mais expressivas prerrogativas asseguradas às formações sociais contemporâneas.

Essa prerrogativa, que se qualifica por seu caráter de metaindividualidade, consiste no reconhecimento de que todos têm direito ao meio ambiente ecologicamente equilibrado.

Trata-se, consoante já o proclamou o Supremo Tribunal Federal (RTJ 158/205-206, Rel. Min. CELSO DE MELLO), com apoio em douta lição expendida por CELSO LAFER ('A Reconstrução dos Direitos Humanos', p. 131/132, 1988, Companhia das Letras), de um típico direito de terceira geração (ou de novíssima dimensão), que assiste, de modo subjetivamente indeterminado, a todo o gênero humano, circunstância essa que justifica a especial obrigação - que incumbe ao Estado e à própria coletividade - de defendê-lo e de preservá-lo em benefício das presentes e futuras gerações, evitando-se, desse modo, que irrompam, no seio da comunhão social, os graves conflitos intergeneracionais marcados pelo desrespeito ao dever de solidariedade na proteção da integridade desse bem essencial, comum a todos quantos compõem o grupo 
social (MACHADO, 2011).

Vale referir, neste ponto, até mesmo em face da justa preocupação revelada pelos povos e pela comunidade internacional em tema de direitos humanos, que estes, em seu processo de afirmação e consolidação, comportam diversos níveis de compreensão e abordagem, que permitem distingui-los em ordens, dimensões ou fases sucessivas resultantes de sua evolução histórica.

Finalmente, cumpre rememorar as razões expostas, em douto parecer, pelo ilustre SubprocuradorGeral da República, Dr. Flávio Giron, ao opinar pela procedência da presente ação direta de inconstitucionalidade, em manifestação aprovada pelo eminente Chefe da Instituição:

Quanto ao mérito, a Constituição Federal foi clara ao estabelecer, em seu artigo 225, que 'todos têm direito ao meio ambiente ecologicamente equilibrado bem de uso comum do povo e essencial à sadia qualidade de vida, impondo-se ao poder público e à coletividade o dever de defendê-lo e preservá-lo para as presentes e futuras gerações'. (...)

Com o intuito de dar maior efetividade ao cumprimento desse dever do Estado em garantir um meio ambiente saudável e ecologicamente equilibrado, foi sancionada a Lei no 9.605, de 12/2/98, denominada de 'Lei dos Crimes Ambientais' que tipifica como crime praticar ato de abuso, maus-tratos, ferir, mutilar, praticar quaisquer atos de crueldade contra os animais. Note-se que a Constituição Federal protege todos os animais, sem discriminação de espécie ou categoria (...). (BRASIL, 2011)

Continuando seu parecer, o Subprocurador-Geral da República impugna os argumentos trazidos pela

Assembleia Legislativa do Estado do Rio de Janeiro nos seguintes termos:

A tese de que os animais domesticados não estão abrangidos pela proteção constitucional não se sustenta, pois não faz sentido que o legislador constituinte tenha resolvido permitir que essa 'categoria' da fauna possa ser objeto de crueldade. Por fim, causa espécie a afirmação de que os galos lutam sem a 'interferência humana', mas por simples 'espírito atávico'. As informações de entidades ambientalistas deixam claro que há todo um processo de preparação e condicionamento dos animais para o combate. Tal processo é conduzido por um treinador, cujos métodos, segundo tais informações, submetem o animal a uma rotina estafante, que não pode ser considerado mero espírito combativo, como quer fazer crer a segunda requerida. É patente a participação humana na preparação desses animais para a rinha. No presente caso, na hipótese de 'briga de galos', a crueldade é gritante. Segundo informações de entidades que visam a proteção dos animais, o espécime sofre maus-tratos desde a época em que é treinado para as chamadas 'rinhas', e, quando efetivamente participam das lutas, os animais brigam até a exaustão ou até a própria morte (...). (BRASIL, 2011)

E, com ânimo de concluir sua explanação, destacando a crueldade pela qual os animais na briga de galos são submetidos, constata a inobservância do legislador estadual ao estabelecido na Constituição Federal, opinando o Ministério Público Federal, pela procedência da ação, para que seja declarada a inconstitucionalidade da referida lei:

De fato, as 'brigas de galos' constituem verdadeira forma de tratar com crueldade esses animais, e a lei estadual impugnada, ao autorizar e disciplinar a realização de competições entre 'galos combatentes', autoriza e disciplina a submissão desses espécimes a tratamento cruel, o que a Constituição Federal não permite.

Cumpre também frisar que a rinha de galos é objeto de apostas, sendo o proprietário do galo vencedor recompensado. Logo, seria ingenuidade imaginar a ausência de ação humana em tal atividade, pois deve-se inferir que os proprietários dessas aves sempre terão em mente o lucro possível pela vitória, logo, as aves sempre deverão demonstrar maior 'afinco' nos treinamentos, aumentando as probabilidades de prêmio na competição.

Isto exposto, opina o Ministério Público Federal, por seu órgão, pela procedência da ação, para ser declarada a inconstitucionalidade da Lei fluminense no 2.895, de 20 de março de 
1998. (BRASIL, 2011)

Sendo assim, em face das razões expostas e considerando, ainda, o parecer da douta ProcuradoriaGeral da República, o Supremo Tribunal Federal julgou procedente a ação direta, para declarar a inconstitucionalidade da Lei no 2.895, de 20 de março de 1998, editada pelo Estado do Rio de Janeiro.

\section{CONCLUSÕES}

Este trabalho buscou realizar um aprofundamento acerca da questão da responsabilidade ambiental, municípios que promulgam leis permitindo brigas de galo, especialmente, o do Rio de Janeiro (Lei Fluminense no 2.895/1998), tendo está sido objeto de Ação Direta de Inconstitucionalidade (ADI no 1.856 - Rio de Janeiro) a qual foi apreciada pelo Supremo Tribunal Federal.

Após, foi realizada uma análise sobre a esfera da responsabilidade ambiental no âmbito penal, buscando através da doutrina e jurisprudência buscar informações de como vem sendo trabalhada a questão, com o objetivo de ampliar o conhecimento da matéria e verificar seus pontos positivos, negativos e as divergências que ocorrem entre os operadores do Direito.

Pela pesquisa realizada, pode-se observar que está cada vez mais sendo percebida a importância fundamental do meio ambiente e que é crescente a preocupação com o mesmo. Esta preocupação vem refletida na legislação, ficando clara em artigos como o artigo 225, da Constituição Federal de 1988, onde diz que o meio ambiente é um bem de uso comum do povo e essencial à vida e impondo ao Poder Público e à coletividade o dever de defendê-lo e preservá-los.

Percebe-se que há a necessidade de se atualizar o instituto da responsabilização em sua área penal, visando alcançar um Estado, interna e externamente, mais aparelhado e mais justo, do ponto de vista ambiental. Além disso, a responsabilidade deve funcionar como um sistema auxiliar ou de retaguarda, e só deve ser acionado quando a ameaça de dano é iminente, ou no caso em que a lesão ocorreu e os outros mecanismos da tutela ambiental não responderam à imputação do agente.

Assim, fica clara também a necessidade de uma melhora na educação ambiental, para que todos tenham conhecimento da extrema importância de um meio ambiente saudável e que é preciso preservá-lo para que também se preserve a vida.

\section{REFERÊNCIAS}

BRASIL. Presidência da República Casa Civil. Constituição da República Federativa do Brasil de 1988. Brasília: DOU, 1988.

BRASIL. Presidência da República Casa Civil. Lei n. 9.605, de 12 de fevereiro de 1998. Dispõe sobre as sanções penais e administrativas derivadas de condutas e atividades lesivas ao meio ambiente, e dá outras providências. Brasília: DOU 1998 a.

BRASIL. Presidência da República Casa Civil. Lei n. 2895, de 20 de março de 1998. Autoriza a criação e a realização de exposições e competições entre aves das raças combatentes (fauna não silvestre) para preservar e defender o patrimônio genético da espécie gallus-gallus. Brasília: DOU, 1998b.

FIORILLO, C. A. P.. Curso de direito ambiental brasileiro. São Paulo: Saraiva, 2005.

MACHADO, P. A. L.. Direito ambiental brasileiro. São Paulo: Malheiros, 2011.

SILVA, J. A.. Direito ambiental constitucional. 5 ed. São Paulo: Malheiros, 2003.

A CBPC - Companhia Brasileira de Produção Científica (CNPJ: 11.221.422/0001-03) detém os direitos materiais desta publicação. Os direitos referem-se à publicação do trabalho em qualquer parte do mundo, incluindo os direitos às renovações, expansões e disseminações da contribuição, bem como outros direitos subsidiários. Todos os trabalhos publicados eletronicamente poderão posteriormente ser publicados em coletâneas impressas sob coordenação da Sapientiae Publishing, da Companhia Brasileira de Produção Científica e seus parceiros autorizados. Os (as) autores (as) preservam os direitos autorais, mas não têm permissão para a publicação da contribuição em outro meio, impresso ou digital, em português ou em tradução. 